\title{
The Effect of the Physical Factors of Parents and Children on Stunting at Birth Among Newborns in Indonesia
}

\author{
Kencana Sari ${ }^{1,2}$, Ratu Ayu Dewi Sartika ${ }^{1}$ \\ ${ }^{1}$ Faculty of Public Health, University of Indonesia, Depok, Indonesia; ${ }^{2}$ National Institute of Health Research and Development, Indonesian Ministry \\ of Health, Jakarta, Indonesia
}

Objectives: This study examined stunting at birth and its associations with physical factors of parents and children in Indonesia.

Methods: This study analyzed secondary data from the national cross-sectional Indonesian Basic Health Survey 2018, conducted across 34 provinces and 514 districts/cities. Birth length data were available for 756 newborns. Univariable, bivariable, and multivariable logistic regression analyses were performed to determine associations between the physical factors of parents and children and stunting at birth.

Results: In total, $10.2 \%$ of children aged 0 months were stunted at birth (10.7\% of males and $9.5 \%$ of females). Stunting at birth was associated with the mother's age at first pregnancy, parity, parents' heights, parents' ages, and gestational age. Children from mothers with short statures (height $<145.0 \mathrm{~cm}$ ) and fathers with short statures (height $<161.9 \mathrm{~cm}$ ) had an almost 6 times higher likelihood of being stunted at birth (adjusted odds ratio, 5.93; 95\% confidence interval, 5.53 to 6.36). A higher maternal age at first pregnancy had a protective effect against stunting. However, other variables (firstborn child, preterm birth, and both parents' ages being $<20$ or $>35$ years) corresponded to a 2-fold higher likelihood of stunting at birth compared to the reference.

Conclusions: These findings provide evidence that interventions to reduce stunting aimed at pregnant females should also consider the parents' stature, age, and parity, particularly if it is the first pregnancy and if the parents are short in stature or young. Robust programs to support pregnant females and monitor children's heights from birth will help prevent intergenerational stunting.

Key words: Stunting, Newborn, Parents, Child, Indonesia

\section{INTRODUCTION}

Stunting at birth is prevalent in low and middle-income countries [1]. In Guatemala, 33\% of young infants ( $<6$ weeks of age) are stunted [2]. In Indonesia, the proportion of children with birth lengths of less than $48 \mathrm{~cm}$ increased from $20.2 \%$ in

Received: March 5, 2021 Accepted: June 24, 2021

Corresponding author: Kencana Sari

Faculty of Public Health, University of Indonesia, Depok 15315,

Indonesia

E-mail: kencana.sw@gmail.com

This is an Open Access article distributed under the terms of the Creative Commons Attribution Non-Commercial License (https://creativecommons.org/licenses/by$\mathrm{nc} / 4.0 / /$ which permits unrestricted non-commercial use, distribution, and reproduction in any medium, provided the original work is properly cited.
2013 to $22.7 \%$ in 2018. However, little information is available about the proportion of newborns who are stunted at birth $[3,4]$. One study showed that the prevalence of stunting in children under 2 years old was 33.7\% in 2013 [5]. The World Health Organization (WHO) set a target for all countries to reduce the prevalence of stunting at birth by $40 \%$ by 2025 [6].

Stunting at birth, measured from the length of birth for age, is an important indicator of both an individual's initial growth and his or her development in later childhood and adult life. One study showed that a short length at birth was a determinant of stunting later in life [7]. Stunting might also increase the risk of experiencing developmental delays and contracting non-communicable diseases later in life [8].

Stunting is often a response to a limited supply of nutrients 
at the cellular level, because of which resources for growth are diverted toward the maintenance of basic metabolic functions [9]. Children who experience stunting at an early age $(<6$ months) tend to face difficulties catching up on regular growth, which results in a shorter stature as an adult. Many studies have examined stunting in children aged 0-23 months or 0-59 months, but few have examined newborns exclusively. Moreover, a lack of information about birth length in some studies prevented further analysis [10]. Stunting at birth must be examined to help understand when stunting prevention programs should be conducted, whether during pregnancy, breastfeeding, or the complementary feeding period, in order to ultimately reduce the prevalence of stunting and prevent limitations of growth at a later age.

There is a growing body of literature investigating the various factors that increase the risk of a short birth length or stunting at birth. One study showed that males are more likely than females to be stunted at birth [2]. A longer duration of pregnancy has also been found to have a significant positive association with an infant's length at birth [11]. A previous study highlighted the need to consider maternal height-a potential indicator of a mother's nutritional status during childhood - as a proxy for intergenerational undernutrition that affects stunting [5]. Most previous studies investigated the association between stunting and maternal height but did not examine the relationship between combined maternal and paternal heights and stunting at birth. Understanding whether stunting has occurred at birth is important for determining appropriate stunting management strategies and ensuring that children's growth, both weight and height indicators, from birth is monitored to prevent inadequate growth and development later in life. Hence, this study aimed to examine stunting at birth and its association with the physical factors of parents and children among newborns in Indonesia.

\section{METHODS}

\section{Study Design}

This study used secondary data from the Indonesian Basic Health Research (RISKESDAS) 2018, a national cross-sectional study that is conducted by the Ministry of Health every 5 years. It collected information related to health indicators, including maternal and child health indicators. The survey aimed to examine the state of public health in Indonesia on the district/ city level, the provincial level, and the national level [3].

\section{Sample Size and Sampling}

The sample selection process of RISKESDAS was designed to represent the national population across 514 districts/cities and 34 provinces in Indonesia. In total, 29824 census blocks were visited out of the 30000 census blocks that were targeted (99.4\%). Additionally, 295720 households were visited, and 1017290 household members were interviewed, with a response rate of $93.2 \%$.

Participants were selected using a two-stage sampling method. The first stage implied stratification of all census blocks from the 2010 population census based on welfare strata. Then, 180000 out of 720000 census blocks were selected after systematic probability proportional to size (PPS) sampling was conducted. Finally, 30000 census blocks were selected systematically using the PPS method in each urban/rural stratum per regency/city. The second stage involved selecting 10 households through systematic sampling with implicit stratification according to household heads' education levels. All household members who stayed or planned to stay in the household for at least 6 months and had the same food source were interviewed. Trained fieldworkers conducted face-to-face interviews using structured questionnaires. Respondents aged 15 and under were accompanied or represented by a parent or guardian during the interview.

For this study, the sample consisted of children aged 0 months for whom birth length data were available. In total, 756 newborns with complete data were included in our analysis.

\section{Study Variables}

The dependent variable was stunting at birth. Birth length data were obtained from childbirth documents: either the mother and child health book provided by the Ministry of Health to every pregnant females in Indonesia, birth certificates, or other legal documents. Health workers measure infants' birth lengths within the first 24 hours after birth according to Indonesia's neonatal care guidelines [12].

Stunting at birth was defined as having a height for age Zscore (HAZ) of less than minus two standard deviations (SD; $<-2$ SDs from the median), based on 2006 WHO child growth standards [13]. WHO Anthro software was used to calculate Z-scores. HAZ is a child nutritional status indicator to determine whether a child's height and growth correspond to his or her age.

The independent variables were the mother's age at first pregnancy, parity, parents' heights, parents' ages, the child's sex, and gestational age. The mother's age at first pregnancy 
was divided into groups ( $<15,15-17,18-19,20-24$, and $\geq 25$ years old). Parity was indicated as $1,2,3$, or $\geq 4$ births. Maternal and paternal heights were measured using a standardized body length, with an accuracy of $0.01 \mathrm{~cm}$. Parental height was shown as the combined height of the mother and father. Maternal and paternal height were categorized as short if they were less than $145.0 \mathrm{~cm} \mathrm{[14]} \mathrm{and} 161.9 \mathrm{~cm}$ [15], respectively. Parental age was classified into three groups: both parents being 20-35 years old, only 1 parent being 20-35 years old, and both parents being $<20$ years old or $>35$ years old. In addition, physical factors related to children consisted of sex and gestational age, which was categorized as either preterm $(<37$ weeks) or full-term ( $\geq 37$ weeks).

\section{Statistical Analysis}

IBM SPSS version 24.0 (IBM Corp., Armonk, NY, USA) was used for analysis. Prior to the analysis, the distribution of body length and HAZ were tested for normality using the Kolmogorov-Smirnov test, which resulted in an abnormal distribution. A binary binomial categorical variable was then created by categorizing subjects as either stunted or not stunted. Descriptive statistics were used to indicate the sample distribution and proportion of newborns with stunting at birth. We used multiple imputations for missing data and assumed random conditions of missingness on observed data. Imputed data were used for univariable analysis of incomplete independent variable data. The chi-square test was conducted to analyze the association between stunting at birth and all independent variables and assess multiple logistic regression candidates. Independent variables with $p$-values of $<0.25$ after the bivariable analysis were included in the multivariable logistic regression analysis [16]. Finally, multivariable logistic regression was conducted using backwards selection. The $p$-values of $<0.05$ were considered to indicate statistical significance in the final model. The logistic regression analysis used sample weight to compare the proportion of stunting at birth according to the mother's age at first pregnancy, parity, parents' heights, parents' ages, child sex, and gestational age.

\section{Ethics Statement}

Ethical approval was received from the Health Research Ethics Committee of the Indonesian Ministry of Health (LB.02.01/ 2/KE.267/2017). Permission to access data from the RISKESDAS 2018 was granted by the National Institute of Health Research and Development of the Indonesian Ministry of Health. Before participating in the survey, written informed consent was obtained from each individual's parents or legal guardians for their participation.

\section{RESULTS}

\section{Characteristics of Respondents}

Table 1 shows that most of the mothers of the 756 participants experienced their first pregnancy within the age range of 20-24 years old (47.0\%), and had a parity of $2(37.6 \%)$. Most of the newborns were delivered after the full-term (74.5\%).

Table 1. Characteristics of the sample, Indonesia in 2018 $(n=756)$

\begin{tabular}{|c|c|}
\hline Characteristics & n (\%) \\
\hline \multicolumn{2}{|l|}{ First pregnancy age (y) } \\
\hline$<15$ & $11(1.5)$ \\
\hline $15-17$ & $57(7.5)$ \\
\hline $18-19$ & $135(17.9)$ \\
\hline $20-24$ & $355(47.0)$ \\
\hline$\geq 25$ & $198(25.2)$ \\
\hline \multicolumn{2}{|l|}{ Parity } \\
\hline 1 & $200(26.5)$ \\
\hline 2 & $284(37.6)$ \\
\hline 3 & $170(22.5)$ \\
\hline$\geq 4$ & $98(18.1)$ \\
\hline \multicolumn{2}{|c|}{ Gestational age when the child was born (wk) } \\
\hline$\geq 37$ & $563(74.5)$ \\
\hline$<37$ & $193(25.5)$ \\
\hline \multicolumn{2}{|l|}{ Child sex } \\
\hline Male & $388(51.3)$ \\
\hline Female & $368(48.7)$ \\
\hline \multicolumn{2}{|l|}{ Parents' heights $(\mathrm{cm})$} \\
\hline Mother $\geq 145.0$, father $\geq 161.9$ & $446(59.0)$ \\
\hline Mother $<145.0$, father $\geq 161.9$ & $48(6.3)$ \\
\hline Mother $\geq 145.0$, father $<161.9$ & $236(31.2)$ \\
\hline Mother $<145.0$, father $<161.9$ & $26(3.4)$ \\
\hline \multicolumn{2}{|l|}{ Parents' ages (y) } \\
\hline Both parents $20-35$ & $433(57.3)$ \\
\hline Either parent 20-35 & $221(29.2)$ \\
\hline Both parents $<20$ or $>35$ & $102(13.5)$ \\
\hline \multicolumn{2}{|l|}{ Stunting at birth } \\
\hline No & $675(89.3)$ \\
\hline Yes & $81(10.7)$ \\
\hline \multicolumn{2}{|l|}{ HAZ } \\
\hline Mean \pm SD (Min-Max) & $-0.55 \pm 1.07(-5.22-3.41)$ \\
\hline
\end{tabular}

HAZ, height for age Z-score; SD, standard deviation; Min, minimum; Max, maximum. 
The proportion of stunting at birth was slightly different between males (51.3\%) and females (48.7\%). A majority of the newborns had mothers and fathers with tall statures (59.0\%) and parents whose ages were both 20-35 years old (57.3\%). The proportion of subjects with stunting at birth was $10.7 \%$.

\section{Distribution of Stunting at Birth}

Figure 1 shows a distribution of stunting at birth by sex. There was no clear distribution pattern of parity according to stunting at birth by sex, but stunting was higher among female firstborn children (12.5\%) than male firstborn children (10.1\%) (Figure 1A). The graph shows that the proportion of stunting at birth was higher among children born preterm (17.0\%) than full-term (8.2\%) and higher among preterm males (26.6\%) than preterm females (9.5\%).

In terms of parents' heights, this study found the highest proportion of subjects who were stunted at birth among children born to a short mother and father (31.1\%). Among this group, more females (38.2\%) were stunted at birth than males
(25.8\%) (Figure 1B). In terms of age, children whose parents were both younger than 20 or older than 35 had the highest proportion of stunted newborns (12.8\%), of which the proportion of males (13.7\%) was higher than females (11.4\%)

\section{Associations Between Parents' and Children's Physical Factors and Stunting at Birth}

Bivariable analysis showed that all variables had a significant association with stunting at birth among newborns $(p<0.05)$. Likewise, after adjustment with all variables, the variables in the final model associated with stunting at birth were the mother's age at first pregnancy, parity, gestational age, parents' heights, and parents' ages (Table 2).

Children of mothers whose first birth was at the age of 25 or older were less likely to be stunted at birth than those in the reference group (adjusted odds ratio [aOR], 0.80; 95\% confidence interval $[\mathrm{Cl}], 0.68$ to $0.95 ; p=0.011)$. Firstborn children were more than 2.31 times more likely to be stunted at birth than non-firstborn children (aOR, 2.31; $95 \% \mathrm{Cl}, 2.16$ to 2.47 ;
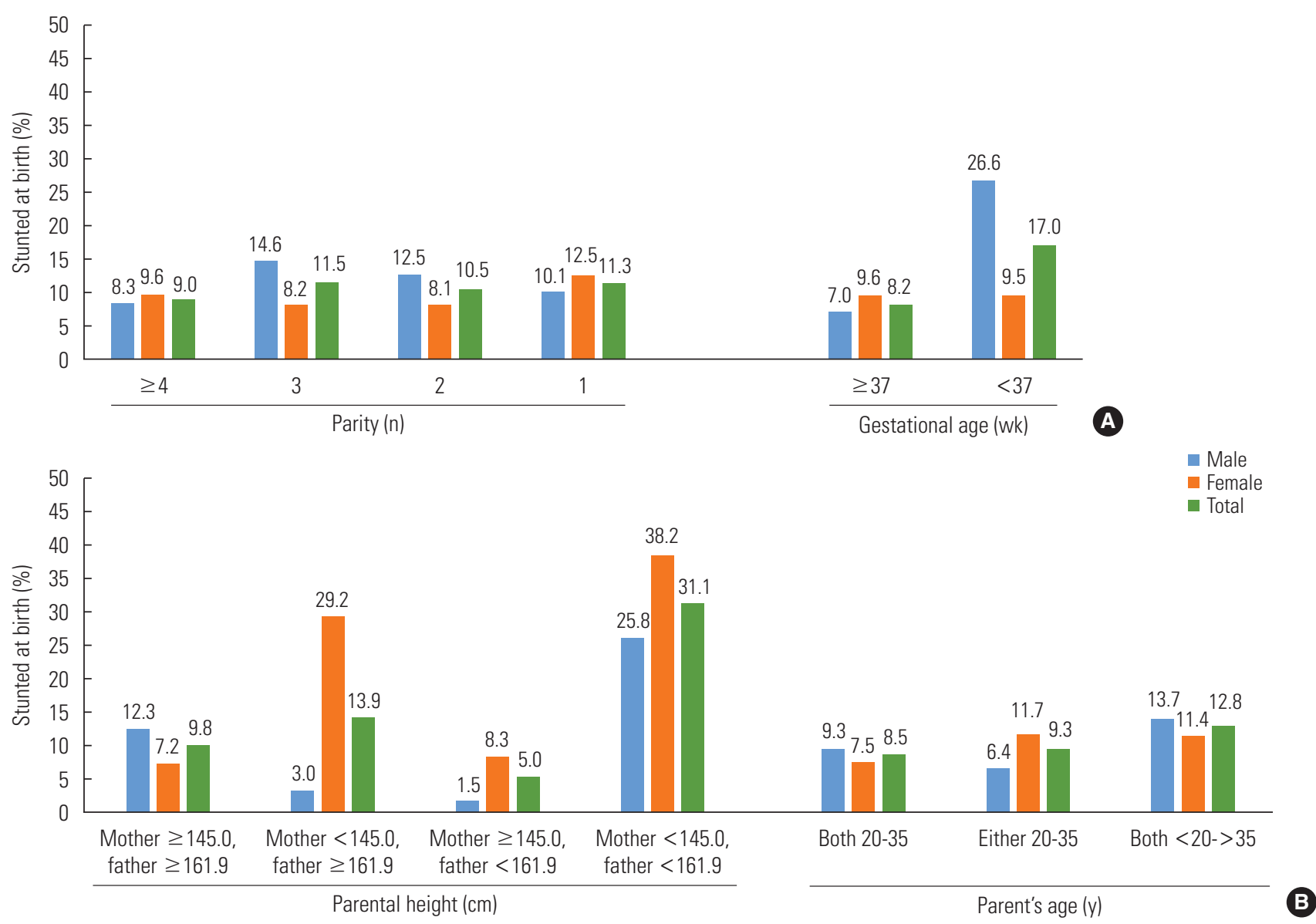

Figure 1. Distribution of stunting at birth according to parity and gestational age (A) and parental height and parent's age (B) by sex among newborns, Indonesia in 2018. 
Table 2. Associations between the distribution of stunting at birth among newborns and parental and child risk factors in Indonesia in 2018

\begin{tabular}{|c|c|c|c|c|c|}
\hline Variables & Stunting at birth (\%) & cOR $(95 \% \mathrm{Cl})$ & $p$-value & aOR $(95 \% \mathrm{Cl})$ & $p$-value \\
\hline \multicolumn{6}{|l|}{ Mother's age at first pregnancy (y) } \\
\hline$<15$ & 5.1 & 1.00 (reference) & & 1.00 (reference) & \\
\hline $15-17$ & 4.2 & $0.81(0.68,0.97)$ & 0.021 & $0.37(0.31,0.45)$ & $<0.001$ \\
\hline $18-19$ & 7.9 & $1.59(1.36,1.87)$ & $<0.001$ & $0.37(0.31,0.45)$ & $<0.001$ \\
\hline $20-24$ & 12.9 & $2.76(2.35,3.23)$ & $<0.001$ & $1.34(1.13,1.58)$ & 0.001 \\
\hline$\geq 25$ & 8.0 & $1.63(1.39,1.92)$ & $<0.001$ & $0.80(0.68,0.95)$ & 0.011 \\
\hline \multicolumn{6}{|l|}{ Parity } \\
\hline$\geq 4$ & 9.0 & 1.00 (reference) & & 1.00 (reference) & \\
\hline 3 & 11.5 & $1.57(1.49,1.66)$ & $<0.001$ & $1.70(1.59,1.82)$ & $<0.001$ \\
\hline 2 & 10.5 & $1.51(1.43,1.59)$ & $<0.001$ & $2.04(1.92,2.18)$ & $<0.001$ \\
\hline 1 & 11.3 & $1.79(1.69,1.90)$ & $<0.001$ & $2.31(2.16,2.47)$ & $<0.001$ \\
\hline \multicolumn{6}{|l|}{ Gestational age (wk) } \\
\hline$\geq 37$ & 8.2 & 1.00 (reference) & & 1.00 (reference) & \\
\hline$<37$ & 17.0 & $2.30(2.23,2.36)$ & $<0.001$ & $2.12(2.05,2.19)$ & $<0.001$ \\
\hline \multicolumn{6}{|l|}{ Child sex } \\
\hline Male & 10.7 & 1.00 (reference) & & & \\
\hline Female & 9.5 & $0.88(0.86,0.90)$ & $<0.001$ & - & - \\
\hline \multicolumn{6}{|l|}{ Parents' heights (cm) } \\
\hline Mother $\geq 145.0$, father $\geq 161.9$ & 9.8 & 1.00 (reference) & & 1.00 (reference) & \\
\hline Mother $<145.0$, father $\geq 161.9$ & 13.9 & $1.49(1.41,1.57)$ & $<0.001$ & $1.59(1.51,1.68)$ & $<0.001$ \\
\hline Mother $\geq 145.0$, father $<161.9$ & 5.0 & $0.48(0.46,0.51)$ & $<0.001$ & $0.54(0.51,0.56)$ & $<0.001$ \\
\hline Mother $<145.0$, father $<161.9$ & 31.1 & $4.16(3.90,4.44)$ & $<0.001$ & $5.93(5.53,6.36)$ & $<0.001$ \\
\hline \multicolumn{6}{|l|}{ Parents' ages (y) } \\
\hline Both parents 20-35 & 8.5 & 1.00 (reference) & & 1.00 (reference) & \\
\hline Either parent 20-35 & 9.3 & $1.12(1.08,1.16)$ & $<0.001$ & $1.50(1.44,1.55)$ & $<0.001$ \\
\hline Both parents $<20$ or $>35$ & 12.8 & $1.59(1.52,1.65)$ & $<0.001$ & $2.37(2.25,2.50)$ & $<0.001$ \\
\hline Constant & - & - & & 0.036 & \\
\hline
\end{tabular}

cOR, crude odds ratio; $\mathrm{Cl}$, confidence interval; aOR, adjusted odds ratio.

$p<0.001)$. The results also showed that preterm newborns were twice as likely to be stunted at birth than babies delivered after the full-term (aOR, 2.12; $95 \% \mathrm{Cl}, 2.05$ to 2.19 ; $p<0.001)$. Children who had a short mother and father were almost 6 times more likely to be stunted at birth than children who had mothers and fathers with an average height (aOR, $5.93 ; 95 \% \mathrm{Cl}, 5.53$ to $6.36 ; p<0.001$ ). In addition, children with parents whose ages were both $<20$ years old or $>35$ years old were more than 2 times more likely to be stunted at birth (aOR, $2.37 ; 95 \% \mathrm{Cl}, 2.25$ to $2.50 ; p<0.001)$ than the reference group.

The summary statistic model showed that the Nagelkerke $R^{2}$ was 0.104 , which suggests that $10.4 \%$ of the variability of stunting at birth could be explained by the mother's age at first pregnancy, parity, gestational age, parents' heights, and parents' ages. This low percentage of explained variance suggests that there were considerably more variables responsible for stunting at birth than were identified in this study.

\section{DISCUSSION}

Our findings show that stunting at birth is experienced by 1 in every 10 newborns in Indonesia. This is lower than the rate of stunted newborns in Guatemala and Ethiopia, both of which have a rate of stunting at birth of around 30\% [2,17]. One report found that the prevalence of stunted growth among children in Indonesia reached its peak within the age range of 12-23 months (37.7\%) then slightly decreased at 24-35 months old (35.6\%) [3]. However, stunting at birth is often overlooked and not followed up during newborn care. Available programs and interventions still mostly focus on low birth weight as an 
essential treatment and outcome indicator $[12,18,19]$. One possible reason for this is that stunting at birth does not cause as much direct harm to infants as low birth weight does to newborns. Policy-makers and stakeholders should consider these findings and adjust existing programs and interventions accordingly for low birth weight and stunting prevention.

In this study, the model showed that a mother's age at first pregnancy of $\geq 25$ years old had a significant protective effect on the odds of a newborn being stunted compared to the reference group. This result aligns with a study of 55 countries that showed that increasing the age at first pregnancy to 27-29 could decrease infant mortality and adverse child health outcomes (stunting, underweight, anemia, diarrhea) [20]. Mothers whose first pregnancies were within the age range of 27-29 (delayed first birth) were more likely to live in better sanitary conditions, have a higher education level, have a higher socioeconomic status, have a partner, and live in an urban area [21]. Advising young females to delay their first pregnancies and apprising them of the potential risks of a young pregnancy, such as adverse child health outcomes, should be included in health education materials for adolescents and young females to increase their awareness. The results of this study showing that a first pregnancy within the age range of 20-24 years old increased the odds of stunting at birth might be due to premature births occurring more than $60 \%$ of the time among mothers in this age range, according to cross-tabulation of the results.

We found that the likelihood of children from first parity (firstborn children) being stunted at birth was 2.31 times higher than the reference group. Cross-tabulation of the results showed that nearly $80 \%$ of mothers experienced their first birth when they were younger than 25 years old. One study found that females who gave birth for the first time when they were younger than 27 years old had lower levels of maturity, lower socioeconomic status, and poorer hygiene compared to females with an older age at first birth [20].

Our findings showed that preterm infants had a higher risk of experiencing stunting as a child, which is consistent with the findings of previous studies [7]. Preterm infants tend to have a lower birth weight and length than full-term infants [3]. One study found that preterm infants had higher levels of plasma insulin-like growth factor binding protein 2 (IGFBP-2), an endocrine regulator of growth, which led to children having a shorter stature. Different levels of IGFBP-2 might be caused by nutritional abnormalities during the perinatal period [22].

Maternal height has been found to be a risk factor for child stunting $[14,23]$. Our findings showed that having both a short mother and father increased the risk of stunting at birth. One study found that genetic factors had a stronger influence on an infant's length at birth than the intrauterine environment [24]. Moreover, a study found that a $0.22-\mathrm{SD}$ and a $0.15-\mathrm{SD}$ increase in an infant's length at birth was positively associated with a 1-SD increase in maternal and paternal height, respectively [25].

The link between parents' heights, socioeconomic status, and intergenerational outcomes (i.e., stunting at birth) can be explained based on 4 factors suggested in a previous study: (1) biomechanical factors (i.e., female's reproductive organs such as pelvic and placental organs), (2) biological factors (i.e., one's metabolism when receiving or transferring nutritional components, poor nutritional stock), (3) genetic factors, and (4) psychosocial factors (i.e., poor living conditions) [9]. A previous study suggested that the father's height can affect a newborn's likelihood of inheriting a gene that affects bone growth throughout pregnancy, while the mother's height can affect a newborn's likelihood of inheriting a gene that affects bone growth at a later period during pregnancy [25]. Therefore, genetics related to paternal and maternal height and environmental factors during childhood are important predictors of a child's stature [26].

However, neither maternal nor paternal height has been used as determining factors when selecting targets for nutrition programs. In addition, the father's height during antenatal care or children's health assessments is rarely considered in practice. This might result in an intergenerational stunting effect in the absence of appropriate interventions to break the cycle.

Our study also found that children from parents who were both aged either $<20$ years old or $>35$ years old were 2.37 times more likely to be stunted at birth compared to their counterparts. The age range of 25-29 is the optimal time for couples to have children to prevent the risk of having a stunted child at birth [20]. At 20 years old and younger, females uteruses and pelvises are not yet fully developed, and pregnancy carries a greater risk of severe preeclampsia, poor fetal growth, and fetal distress. For female $>35$ years, pregnancy carries a high risk of preterm delivery, severe preeclampsia, hypertension [27]. This suggests that a mother's age at pregnancy could result in a poor birth outcome that stunts a child's potential growth.

Having a child who is stunted at birth might also correlate in part to the readiness and maturity of the father, especially a first-time father. Young fathers tend to have a relatively low socioeconomic status and education level, which makes them 
less likely to have access to prenatal or antenatal health services and household food security. Additionally, advanced paternal age could also result in certain health risks due to chromosomal mutations and abnormalities [28], and having a father who is old and less physically energetic could also potentially undermine a child's growth and development.

The present study makes several noteworthy contributions to research on the correlation between the physical factors of parents and children with stunting at birth. Previous studies have only focused on maternal variables (e.g., mothers' height and age) and have not considered fathers' height nor mothers' and fathers' heights combined $[2,17]$. This study generated further evidence that stunting occurs from birth and should be prevented since stunting is hard to reverse later in life [29]. Furthermore, these findings are also important since the birth length of all newborns was measured and recorded as a basis for future child growth monitoring, as only $47.9 \%$ of under- 5 children had recorded birth lengths [3]. Lastly, the data source for this study represented national-level data in which the procedures and instruments were validated (i.e., the data collectors had health science background, training, and supervision).

There were some limitations to this study. The survey relied on documented records that collected data on infants' length at birth. Thus, infants who did not have a recorded birth length were not included, and findings may not be representative of all newborns. The role of other parental and environmental factors before and during pregnancy were also not considered in this study. Further studies that focus on mothers' diets, nutritional intake, health-seeking behaviors, and weight gain during pregnancy are therefore recommended.

Nevertheless, despite the relatively low rate of stunting at birth in Indonesia, stunting still remains a potential future public health problem that demands action. This study showed that the mother's age at first pregnancy, parity, parents' heights, parents' ages, and gestational age were significantly associated with stunting at birth. Efforts to reduce stunting should thus consider parents' stature, age, and parity, especially for first-time pregnancies, and if parents are short in stature or young. Our findings suggest the need to implement robust programs for supporting pregnant women and children. Education and counseling should be provided to improve parents' awareness about birth outcomes and the consequences of stunting on childhood growth, delaying first pregnancy, record and consider the characteristics of parents, and monitor children's heights from birth as effective strategies to prevent intergenerational stunting.

\section{CONFLICT OF INTEREST}

The authors have no conflicts of interest associated with the material presented in this paper.

\section{FUNDING}

None.

\section{ACKNOWLEDGMENT}

None.

\section{AUTHOR CONTRIBUTIONS}

Conceptualization: KS. Data curation: KS. Formal analysis: KS. Funding acquisition: None. Methodology: KS, RADS. Project administration: KS. Visualization: KS. Writing - original draft: KS. Writing - review \& editing: KS, RADS.

\section{ORCID}

Kencana Sari $\quad$ https://orcid.org/0000-0003-1382-1492

Ratu Ayu Dewi Sartika https://orcid.org/0000-0001-50187625

\section{REFERENCES}

1. United Nations Children's Fund (UNICEF). Improving child nutrition: the achievable imperative for global progress; 2013 [cited 2021 Mar 1]. Available from: https://data.unicef.org/resources/improving-child-nutrition-the-achievable-imperative-for-global-progress/.

2. Solomons NW, Vossenaar M, Chomat AM, Doak CM, Koski KG, Scott ME. Stunting at birth: recognition of early-life linear growth failure in the western highlands of Guatemala. Public Health Nutr 2015;18(10):1737-1745.

3. Indonesian Ministry of Health. 2018 Indonesian Basic Health Research (RISKESDAS) survey. Jakarta: Lembaga Penerbit Balitbangkes; 2019, p. 423-427 (Indonesian).

4. National Institute of Health Research and Development. Basic Health Survey in number. Jakarta: Lembaga Penerbit Balitbangkes; 2013, p. 319 (Indonesian).

5. Titaley CR, Ariawan I, Hapsari D, Muasyaroh A, Dibley MJ. Determinants of the stunting of children under two years old in 
Indonesia: a multilevel analysis of the 2013 Indonesia Basic Health Survey. Nutrients 2019;11(5):1106.

6. World Health Organization. Global nutrition targets 2025: stunting policy brief; 2014 [cited 2019 Oct 3]. Available from: https://www.who.int/publications/i/item/WHO-NMH-NHD14.3.

7. Beal T, Tumilowicz A, Sutrisna A, Izwardy D, Neufeld LM. A review of child stunting determinants in Indonesia. Matern Child Nutr 2018;14(4):e12617.

8. Barker DJ, Osmond C, Kajantie E, Eriksson JG. Growth and chronic disease: findings in the Helsinki Birth Cohort. Ann Hum Biol 2009;36(5):445-458.

9. Perkins JM, Subramanian SV, Davey Smith G, Özaltin E. Adult height, nutrition, and population health. Nutr Rev 2016;74(3): 149-165.

10. Martorell R, Zongrone A. Intergenerational influences on child growth and undernutrition. Paediatr Perinat Epidemiol 2012; 26 Suppl 1:302-314.

11. Pawlus B, Wiśniewski A, Kubik P, Milde K, Gmyrek L, Pęsko E. Birth body length, birth body weight and birth head circumference in neonates born in a single centre between 2011 and 2016. Ginekol Pol 2017;88(11):599-605.

12. Indonesian Ministry of Health. Handbook of essential neonatal heath service. Jakarta: Kementerian Kesehatan; 2010, p. 16 (Indonesian).

13. World Health Organization. WHO child growth standards: training course on child growth assessment; 2008 [cited 2019 Oct 3]. Available from: https://www.who.int/childgrowth/training/module_c_interpreting_indicators.pdf.

14. Khatun W, Rasheed S, Alam A, Huda TM, Dibley MJ. Assessing the intergenerational linkage between short maternal stature and under-five stunting and wasting in Bangladesh. Nutrients 2019;11(8):1818.

15. Candra A, Puruhita N, Susanto JC. Risk factors of stunting among 1-2 years old children in Semarang City. Media Med Indones 2011;45(3):206-212.

16. Zhang Z. Model building strategy for logistic regression: purposeful selection. Ann Transl Med 2016;4(6):111.

17. Gonete AT, Kassahun B, Mekonnen EG, Takele WW. Stunting at birth and associated factors among newborns delivered at the University of Gondar Comprehensive Specialized Referral Hospital. PLoS One 2021;16(1):e0245528.

18. World Health Organization. Pregnancy, childbirth, postpartum and newborn care: a guide for essential practice; 2015 [cited
2020 Aug 27]. Available from: https://apps.who.int/iris/handle/10665/249580.

19. National Team for the Acceleration of Poverty Reduction. National strategy for acceleration of stunting prevention 20182024. Jakarta: Sekertariat Wakil Presiden Republik Indonesia; 2018, p. 42 (Indonesian).

20. Finlay JE, Özaltin E, Canning D. The association of maternal age with infant mortality, child anthropometric failure, diarrhoea and anaemia for first births: evidence from 55 low- and middle-income countries. BMJ Open 2011;1(2):e000226.

21. Ozaltin E, Hill K, Subramanian SV. Association of maternal stature with offspring mortality, underweight, and stunting in low- to middle-income countries. JAMA 2010;303(15):15071516.

22. Rowe DL, Derraik JG, Robinson E, Cutfield WS, Hofman PL. Preterm birth and the endocrine regulation of growth in childhood and adolescence. Clin Endocrinol (Oxf) 2011;75(5):661665.

23. Addo OY, Stein AD, Fall CH, Gigante DP, Guntupalli AM, Horta $\mathrm{BL}$, et al. Maternal height and child growth patterns. J Pediatr 2013;163(2):549-554.

24. Jelenkovic A, Yokoyama Y, Sund R, Hur YM, Harris JR, Brandt I, et al. Associations between birth size and later height from infancy through adulthood: an individual based pooled analysis of 28 twin cohorts participating in the CODATwins project. Early Hum Dev 2018;120:53-60.

25. Wills AK, Chinchwadkar MC, Joglekar CV, Natekar AS, Yajnik $\mathrm{CS}$, Fall $\mathrm{CH}$, et al. Maternal and paternal height and BMI and patterns of fetal growth: the Pune Maternal Nutrition Study. Early Hum Dev 2010;86(9):535-540.

26. Young MF, Nguyen PH, Gonzalez Casanova I, Addo OY, Tran LM, Nguyen S, et al. Role of maternal preconception nutrition on offspring growth and risk of stunting across the first 1000 days in Vietnam: a prospective cohort study. PLoS One 2018; 13(8):e0203201.

27. Cavazos-Rehg PA, Krauss MJ, Spitznagel EL, Bommarito K, Madden T, Olsen MA, et al. Maternal age and risk of labor and delivery complications. Matern Child Health J 2015;19(6):12021211.

28. Bray I, Gunnell D, Davey Smith G. Advanced paternal age: how old is too old? J Epidemiol Community Health 2006;60(10): 851-853.

29. Desmond C, Casale D. Catch-up growth in stunted children: definitions and predictors. PLoS One 2017;12(12):e0189135. 